\title{
The impact of flooding disruption on the spatial distribution of commuter's income $^{1}$
}

\author{
Paul Kilgarriff A, Thomas K.J. McDermott BF, Amaya Vega C, Karyn Morrissey D, Cathal \\ $O$ 'Donoghue E
}

A Teagasc Rural Economy and Development Programme, Ireland

B Socio-Economic Marine Research Unit (SEMRU), Whitaker Institute, National University of Ireland, Galway, Ireland

C School of Business, Galway-Mayo Institute of Technology (GMIT), Ireland

D European Centre for Environment and Human Health, University of Exeter Medical School, UK

E College of Arts, Social Sciences and Celtic Studies, National University of Ireland, Galway, Ireland

F Grantham Research Institute, London School of Economics, UK

This is an Accepted Manuscript of an article published by Taylor \& Francis in Journal of Environmental Economics and Policy. on the $11^{\text {th }}$ August 2018, available online at: https://doi.org/10.1080/21606544.2018.1502098.

\subsection{Abstract}

Flooding already imposes substantial costs to the economy. Costs are expected to rise in future, both as a result of changing weather patterns due to climate change, but also because of changes in exposure to flood risk resulting from socio-economic trends such as economic growth and urbanisation. Existing cost estimates tend to focus on direct damages, excluding potentially important indirect effects such as disruptions to transport and other essential services. This paper estimates the costs to commuters as a result of travel disruptions caused by a flooding event. Using Galway, Ireland as a case study, the commuting travel times under the status quo and during the period of the floods and estimated additional costs imposed, are simulated for every commuter. Results show those already facing large commuting costs are burdened with extra costs with those in rural areas particularly vulnerable. In areas badly affected, extra costs amount to $39 \%$ of earnings (during the period of disruption), while those on lower incomes suffer proportionately greater losses. Commuting is found to have a regressive impact on the income distribution, increasing the Gini coefficient from 0.32 to 0.38 .

JEL codes: Q54, R1 1, R41

\footnotetext{
${ }^{1}$ This research has been funded by the Environmental Protection Agency under the EPA Research Programme 2014-2020 (project code 2015-CCRP-DS.10), and forms part of a larger research project, based at UCC and in collaboration with the Grantham Research Institute on Climate Change and the Environment at the London School of Economics, which aims to estimate costs of climate impacts for Ireland and explore policy responses for managing climate risks, with a particular focus on the issue of flooding.

Special thanks to Mark Conroy (Galway County Council) for helping us source the flooded roads data used in this analysis
} 
Keywords: flooding, climate change, transport disruptions, micro-simulation

\subsection{Introduction}

Beginning with Storm Desmond in early December and followed by storms Eva and Frank, the winter of 2015/16 represented the wettest winter on record for Ireland. Rainfall levels in some areas were two and a half times the seasonal average, with over half of all stations recording their wettest winter on record (Met Éireann, 2016). Extensive flooding around the country caused widespread damage. Hundreds of homes and businesses were flooded, and thousands more were cut off by flood waters. Nationally, €1.8 million in humanitarian assistance was paid out to affected households; close to $€ 1 \mathrm{~m}$ to farmers; local authorities received special funding of $€ 18 \mathrm{~m}$ for clean-up costs; while damage to the road network was estimated at over $€ 100 \mathrm{~m}$. In County Galway humanitarian assistance for 162 households totalled $€ 256,000$, clean-up costs $€ 3.1 \mathrm{~m}$ and 80 houses were inaccessible. Aside from damages, the flooding also caused substantial disruptions to everyday life (350,000 customers suffered disruptions to electricity supply, and 23,000 households were placed on boil water notices). The flooding also resulted in substantial travel disruptions; in particular as a result of flooding on the road network (National Directorate for Fire and Emergency Management, 2016). For many areas of County Galway this was the second major flooding event since 2009 (OPW, 2016; OPW, 2009).

In an Irish context climate change is expected to bring more extreme weather conditions and an increased likelihood of river and coastal flooding (Sweeney et al., 2008). While Storm Desmond was considered a 1-in-1 00 year event, a near-real time attribution analysis found that events such as Storm Desmond. are now a 1-in-72 year event (van Oldenborgh et al., 2015). Guerreiro et al. (2018) analysing changes in flooding, droughts and heat waves in 571 European cities using climate models found Great Britain \& Ireland to have some of the highest projected increase in flooding. In the high impact scenario the cities of Cork and Waterford see increases above $80 \%$. To manage this flood risk effectively more information about the economic costs of flooding and its impact on economic activities in the short, medium and long term is required (Field et al., 2014; OECD, 2014). Furthermore this information can help inform policy on the impact of flooding on income groups and inequality (Walker and Burningham, 2011).

With further warming (NOAA, 2017), flood risk will likely increase in many areas, both as a result of more intense precipitation events, and as a consequence of sea level rise (IPCC, 2012; IPCC, 2013). For example, according to the Intergovernmental Panel on Climate Change (IPCC), there is very high confidence that coastal and low-lying areas will increasingly experience adverse impacts such as submergence, coastal flooding, and coastal erosion as a result of projected sea level rise throughout the $21^{\text {st }}$ century and beyond (IPCC 2014). Recent updates of projections for sea level rise have tended to involve upward revisions to expectations - for example, estimates for global mean sea level rise by 2100 increased from a projected 18 to $59 \mathrm{~cm}$ in the IPCC's fourth assessment (IPCC, 2007), to 26 to $98 \mathrm{~cm}$ in the fifth assessment (IPCC, 2013).

According to Dawson et al. (2018), infrastructure investments, which are typically large (costly) and lack flexibility once built, are also sensitive to climate. In particular they note that gradual shifts in long-term climate "will reduce the capacity and efficiency of some infrastructure", while "increases in the frequency of severe weather events, such as flooding ... will lead to increased disruption to 
infrastructure" (p.2). As a result, these authors suggest that "assessing climate risks to infrastructure must therefore be a priority", while also noting that currently "very few assessments prioritize and rank the risks identified, even in relative terms" (p.5).

The UK's Climate Change Risk Assessment (CCRA, 2012) also highlights risks to the transport network from flooding, in the form of disruptions to transport services, as well as the risk that flooding can compromise the integrity of roads and bridges, for example, through scouring. Bad weather conditions can also impact on an individual's ability to carry out daily activities. For example, Marsden et al. (2016) in a six city UK survey found $55 \%$ of respondents reported bad weather impacting on daily activities at least once in the last year with $30 \%$ reporting bad weather frequently impacting on work.

When measuring the impacts of an extreme weather event, there is a focus on the direct costs (destruction of assets and damage to buildings and infrastructure) (FEMA, 2001). In contrast the value of indirect costs (Hallegatte and Przyluski, 2010) or higher-order effects (Rose, 2004), for example costs borne by the general public due to infrastructure damage, are less frequently quantified (OECD, 2014). Input-output models (Cochrane, 1975; Rose et al., 1997) or Computable General Equilibrium models (Tatano and Tsuchiya, 2008; Partridge and Rickman, 1998) may be used to measure both the direct and indirect costs. However, highorder effects can be difficult to verify and require complicated economic models (Rose, 2004). High-order effects such as commuting costs as a result of transport disruption can be large (Gordon et al., 1998) and are worth consideration despite the difficulty of measurement. One study estimated the cost of flood related disruption to major roads at peak times in London of at least $€ 146,000$ per hour (Arkell and Darch, 2006).

The blocking or closure of access routes can add not only extra time and expense to the daily commute but also unwarranted stress and uncertainty (Thieken, 2016). Pregnolato et al. (201 7a) discovered that travel times may increase by more than 50\% due to extreme events. Road closures may cause congestion on segments of road which otherwise would not experience congestion (non-recurrent congestion). The less control commuters have over aspects such as traffic congestion and time pressure, the more stressful commuting can be (Lyons and Chatterjee, 2008). Over time, of course, commuters can adapt to these new road conditions and save time (Zhu et al., 2010) - for example, more flexible working arrangements might be used to help alleviate this stress (Lucas and Heady, 2002).

Research in relation to the impact of climate change on transport disruptions tend to focus on commuting patterns (Arkell and Darch, 2006; Jenelius and Mattsson, 2012; Jenelius and Mattsson, 2015; Pregnolato et al., 2017a; Pregnolato et al., 2017b), resilience of transport networks (Esposito, 2016; Jaroszweski et al., 2014; Kermanshah et al., 2014) and journey times (Pregnolato et al., 2016). This paper builds on the literature by utilising a real-life dataset as opposed to predictive flood hazard mapping. Georeferenced flooded road data collected by Galway county council during the 17 day period of disruption is used. This data highlights how Big Spatial Data shared through open data initiatives can be utilised in a meaningful manner (Harris et al., 2017). While measuring the disruption is not novel in itself this aspect is added to by monetising the disruption and calculating the impact on income and inequality. Previous studies focusing on the impact of flooding on socio-demographic and economic characteristics are hampered by a lack of income data at a detailed spatial scale (Ford et al., 2015a). 
Any disruption to commuting will impact on an individual's level of welfare. Welfare may be defined using monetary and non-monetary aspects (Barr, 1998). An individual's welfare can be increased if their potential to consume is increased. Anything that increases that potential should be considered in a complete measure of welfare (Atkinson, 1983). The Stiglitz-SenFitoussi Commission (2009) highlighted the need for a broadening of income measures to include non-market measures such as commuting. Monetary costs of commuting will depend upon the mode of transport and distance travelled. The time spent commuting will reduce the amount of leisure time available for other activities and therefore has an opportunity cost (Becker, 1965). Related to commuting is the importance of place. Where a person lives is a large determinant of whether they work, where they work and earnings. There will also be a trade-off between commuting and housing costs. Rural residents may trade-off lower housing costs for lower wages in local labour markets (Kain, 1962), whereas those who commute to urban labour markets trade-off higher wages for the disamenity of commuting (So et al., 2001). Rural areas are likely to be net senders of workers to urban areas, highlighting the potential disruption to businesses if workers are unable to travel due to transport disruptions (Hazans, 2004). Debionne et al. (2016) found in an examination of commuter exposure to a flooding event, that commuters with the longest commutes and residents of rural areas to be the most exposed.

Commuting in Ireland involves substantial costs, in the form of the monetary costs of travel (ticket prices or the cost of fuel and other running costs for car drivers), as well as the welfare cost of the lost time spent commuting (Vega et al., 2016). Examining the welfare costs of commuting in Ireland, previous research estimated the combined commuting costs as equivalent to about $30 \%$ of daily wages for the average commuter in the commuter belt around Dublin, about 26\% for the average commuter in Co. Galway and 20\% in Co. Cork (see Vega et al., 2016). These costs reflect in part the heavy reliance on private car as mode of transport (76\% in the Greater Dublin Area, 95\% elsewhere in the country), as well as recent patterns of spatial development such the increasing urban sprawl around Dublin into areas with poor public transport infrastructure. The very high levels of car dependence, especially outside of Dublin, also highlight the Irish economy's vulnerability to disruptions to the road network.

Using the output from a spatial microsimulation approach allows us to estimate welfare at a small area level (Chin and Harding, 2006). When there is a lack of income information in census data, spatial microsimulation enables us to overcome this difficulty, by making use of income data from surveys. Whereas census data contains spatial data, it contains no information on income. Survey data however contains income information but does not have a spatial component. Spatial microsimulation links the two data sources to overcome the lack of data in each (Morrissey and O'Donoghue, 2013). By combining this data with travel to work data it is possible to examine the socio-economic characteristics of commuters impacted by the disruption.

This study adds to existing literature which previously examined the vulnerability of socioeconomic groups to extreme weather events (Masozera et al., 2007). Studies in this area tend to focus on the vulnerability to extreme weather events in developing versus developed nations (Ferreira et al., 2011; Jongman et al., 2015; Kahn, 2005). Winsemius et al. (2018) examined within country however lacked the high resolution spatial data to examine the relationship between poverty and exposure to flooding at a local level (Winsemius et al., 2018). Utilising detailed commuting and income data the impact of flood disruption across income groups is calculated. 
Using Galway as a case study this paper measures the costs to commuters (monetary \& time costs) associated with the flooding of the road network. Specifically, combining timestamped road closure data collected by Galway County Council in the aftermath of Storm Desmond (December 2015) with the Open Street Map road network, data on individuals' place of residence and place of work (CSO, 2011) and micro-simulated income data (O'Donoghue et al., 2012), this paper simulates the impact of storm Desmond on commuters in County Galway by measuring the additional commuting costs associated with the disruption. These costs are firstly measured in terms of additional commuting time and distance using an Origin-Destination (OD) cost matrix. Information on commuting costs and estimates of VoT are then used to convert this additional commuting time into monetary and welfare effects. Analysing the additional commuting costs and commuters' income (SMILE model), the impact on the income distribution is also measured.

\subsection{Data}

\section{Commuting Data}

The Place of Work School Census of Anonymised Records (POWSCAR) dataset is a spatially referenced dataset which contains information for the entire population of the Republic of Ireland on their daily commute, collected as part of the national Census. This dataset has already been used to analyse traffic emissions (Brady and O'Mahony, 2011) traffic simulation (Suzumura et al., 2015) and mode choice for school children (Kelly and Fu, 2014). The data is made available as part of the Small Area Population Statistics (SAPS) Census data aggregated to the electoral division (ED) level. There are 3,440 EDs in Ireland with a mean population of 1,345. Individuals in the POWSCAR data are coded to their place of residence ED as well as their place of work/school/college ED. The POWSCAR data contains information on the residential ED, work ED, journey time and travel mode. However, distance to work is missing. For this reason an OD cost matrix approach is used to estimate journey time and distance for each individual commuter in our study area.

The modal share for County Galway illustrates the high reliance on the car $(88 \%$ modal share) with only $12 \%$ of commuters using public transport daily; this is lower when only rural areas are considered (2\%) (CSO, 2011).

\section{Study Area}

The impact of flooding is examined at the electoral division scale. The study area Galway City \& County is subdivided into 234 electoral divisions. Table 1 shows a number of socioeconomic and demographic indicators for the region. The city is characterised by having a highly educated, working age population, whereas the county has both a high rate of elderly and youth dependency ratios compared to the national average. The unemployment rate for both city and county is below the national average although the at-risk of poverty is higher.

Table 1: Regional Summary Statistics

\begin{tabular}{|l|l|l|l|l|}
\hline & \multicolumn{2}{|l|}{ Galway } & & \\
\hline & City & County & $\begin{array}{l}\text { Greater Dublin } \\
\text { Area }\end{array}$ & National \\
\hline Old Dependency & $12.6 \%$ & $19.4 \%$ & $15.2 \%$ & $17.4 \%$ \\
\hline Youth Dependency & $22.3 \%$ & $35.0 \%$ & $30.5 \%$ & $31.9 \%$ \\
\hline Employment Rate & $56.4 \%$ & $60.3 \%$ & $61.0 \%$ & $58.8 \%$ \\
\hline
\end{tabular}




\begin{tabular}{|l|l|l|l|l|}
\hline Working Age Share & $74.1 \%$ & $64.8 \%$ & $68.7 \%$ & $67.0 \%$ \\
\hline Unemployment Rate & $11.8 \%$ & $12.4 \%$ & $11.9 \%$ & $12.7 \%$ \\
\hline No car households & $23.7 \%$ & $11.2 \%$ & $20.7 \%$ & $17.5 \%$ \\
\hline Tertiary Education Share & $40.9 \%$ & $36.6 \%$ & $38.8 \%$ & $36.2 \%$ \\
\hline At Risk Poverty & $17.6 \%$ & $17.5 \%$ & $13.2 \%$ & $16.0 \%$ \\
\hline Pop. Density & 1,489 & 29 & 247 & 65 \\
\hline Population & 75,529 & 175,124 & $1,927,053$ & $4,588,252$ \\
\hline$\%$ of Pop & $1.6 \%$ & $3.8 \%$ & $42.0 \%$ & $100.0 \%$ \\
\hline
\end{tabular}

Source: SAPS 2011, SMILE

\section{Travel Costs}

An individual's commuting costs consist of the costs associated with the mode of transport and distance travelled and the time costs of the time forgone (Becker, 1965). Generalised transport costs should provide a full measure where possible and capture time, travel cost, reliability and crowding benefits, where relevant (DfT, 2014).

Our Subjective Value of Travel Time (SVTT) values are from Vega et al. (2016). They estimated the SVTT for three subsample of the Irish population using data from the 2011 Census of Population of Ireland. The Value of Time (VoT) is the value the average person places on an hour of their time (Ford et al., 2015b). Overall, the SVTT for commuting in Galway is $€ 21.2 /$ hour for city commuters and $€ 6.07 /$ hour for rural areas. Vega et al. (2016) suggest the high value for the city may reflect heavy traffic congestion due to limited public transport options and in some cases, longer commuting distance. Overall, the values obtained from the analysis are in line with those used by the Department of Transport Common Appraisal Framework (DTTAS, 2016).

For direct travel costs estimates from the NTA (2011) are used. This measure per km considers the standing costs (insurance, car licence and depreciation) of owning a 1200cc $1500 \mathrm{cc}$ car, petrol costs and any wear and tear to the vehicle. The public transport costs are calculated using the average cost for a single ticket including bus and rail. The costs are detailed in Table 2. These costs are broadly in line with the subsistence payments which public sector workers receive for 'mileage' (Impact Trade Union, 2009) and also the AA's published annual cost of motoring (AA, 2016).

Table 2: Transport costs per $\mathrm{km}$ by mode

\begin{tabular}{|l|l|}
\hline Transport Costs per km & $€$ \\
\hline Car Costs & \\
\hline Urban Area & 0.62 \\
\hline Work in Urban Area & 0.63 \\
\hline Rest & 0.58 \\
\hline Public Transport & \\
\hline Galway & 0.15 \\
\hline
\end{tabular}

Source: NTA (2011)

The two cost functions are combined to get equation 1, which is total cost of a one way commute for a commuter. 


$$
\text { Cost }=\left(\text { Distance. } * T C_{m p}\right)+\underset{60 \sim T i m e *}{\sim} \sim \operatorname{VoT} \text {, }
$$

Where distance is from place of residence to place of work for commuter $c, T C$ the transport cost per $\mathrm{km}$ for transport mode $m$ in location $p$, Time the journey time from residence to work for commuter $c$, and $V o T$ is the estimated value of time in location $p$.

\subsection{Spatial Microsimulation}

Aside from estimating the magnitude of the disruption to travel caused by flooding in terms of additional journey times and associated costs, this study examines how this burden is distributed across income groups. In order to understand how the additional costs imposed by flooding are distributed across socio-economic groups, spatially referenced micro-data is required.

As noted above, POWSCAR data is the only population data source for Ireland with detailed individual commuting information. This data however contains no income information. In contrast, the Survey on Income and Living Conditions (SILC) is a nationally representative micro-dataset containing demographic and socio-economic characteristics, including income, employment and household composition statistics (CSO, 2013). This data however is only available at a coarse spatial scale, the NUTS2 region of which there are only two regions for Ireland. Any analysis using the SILC survey is constrained to the national level. Furthermore, the SILC dataset does not contain commuting data. Using a matching algorithm to link the SILC data with the small area level SAPS and POWSCAR data, a spatially detailed dataset is created which allows an examination of the value of commuting travel times relative to disposable income across the Irish regions. One can use spatial microsimulation techniques to accomplish this (O'Donoghue et al., 2013; Chin and Harding, 2006; Ballas et al., 2007).

The development and application of spatial microsimulation models offers considerable scope and potential to analyse the individual composition of an area, so that specific policies may be directed to areas with the greatest need for that policy (Birkin and Clarke, 2012). The data from the Simulated Model of the Irish Local Economy (SMILE) presents a measure of income after taxes and benefits at an individual and household scale and is used to overcome the lack of spatially disaggregated income data. SMILE utilises a data fusion process where micro data is matched using a statistical algorithm with census data to generate spatial micro data (O'Donoghue et al., 2013). The SMILE model uses a Quota Sampling (QS) methodology (Farrell et al., 2010) which reweights survey data according to the quotas for each area. First the micro data is randomly ordered. This micro data is then sampled from until the quotas which are set by the constraint variables from the census - are filled. This step is followed by a calibration method which assigns market incomes to these households. The tax-benefit microsimulation component of SMILE presents a measure of disposable income for each household (O’Donoghue et al., 2013). The dataset created by SMILE contains demographic, socio-economic, labour force and income variables at the micro-level for both individuals and family units. For a complete technical overview of the SMILE and the Quota Sampling methodology please see (Farrell et al., 2013b; Farrell et al. (2013a)).

The data created in SMILE is synthetic data. Validation of the output created by SMILE is an integral component of the model's construction. Calibration through alignment (Morrissey and O'Donoghue, 2011; Morrissey et al., 2013) offers a method to ensure that the output produced by the SMILE model is consistent with real world data. A full description and 
application of the calibration method in terms of labour force and income distributions and socio-economic characteristics and health service utilisation is provided by Morrissey and O'Donoghue, (2011) and Morrissey et al., (2013), respectively. Where data did not previously exist, out-of-sample validation is also utilised. This method of validation involves comparing the synthetic data with new external data, with the data in both datasets aggregated to the same spatial scale. In the case of the SMILE model, external at-risk of poverty estimates from Watson (2005) are utilised for out-of-sample validation. Poverty estimates from SMILE simulated data, are compared with estimates from the external data. Post calibration, SMILE produces a population dataset which contains income and demographic data at the ED level (Vega et al., 2016). After linking the POWSCAR to the SMILE data a new dataset is created which contains individual socio-demographic and economic information as well as information on their commuting time, distance and mode. Linking this data to the OD cost matrix calculated in this paper, the impact of the flooding disruption on the spatial distribution of employment income at the electoral division level is measured.

\section{Sample Selection}

Our data concerns flooded roads, which mainly cause disruption to motor vehicles. For this reason pedestrians, cyclists or train users are not included in the analysis (bus users are included). Only individuals who are in employment and commute are included. Students, those who work from home or the unemployed are not included. This analysis is also restricted to commuters whose journeys start and end within County Galway. As data on the extent or precise locations of flooding on the road network outside of County Galway was unavailable, the analysis reported here cannot say whether commuters traveling outside the county had their journeys disrupted. It would be incorrect to assume that commuters travelled unimpeded once outside County Galway - for example, the town of Athlone which lies just outside the Galway county boundary was particularly badly affected by flooding during this same period (Pope, 2016). This data constraint would tend to cause us to underestimate the total cost of the disruption to travel caused by the flooding in County Galway. After removing individuals living or working outside of County Galway as well as the other specifications mentioned, the sample comprises 48,000 individuals.

\subsection{Methodology Network Analysis}

The Network Analysis is conducted in ArcGIS using the Network Analysis tool. First a Network Dataset (ND) is created utilising the OpenStreetMap data. This ND is required for the OD cost matrix to be calculated. The ED centroid points are used as both the origin and destination points. For data confidentiality reasons the POWSCAR only reports an individual's origin ED and destination ED. No detail is given on the location of residence or place of work within the ED. The OD cost matrix function in ArcGIS 'solves' by calculating a time and distance from each origin to every other destination. The process outputs the quickest time along the road network and corresponding distance.

\section{Building the Network Dataset}

The open source dataset OpenStreetMap ${ }^{2}$ (Haklay and Weber, 2008) which contains detailed information on roads, paths and cycle lanes is used as the road network data. This data has missing information on speed limits and no congestion data. Irish road numbering is also

${ }^{2} \overline{\text { http://download.geofabrik.de/europe/ireland-and-northern-ireland.html }}$ 
missing which is required for matching information in relation to which roads were closed. The speed values are attributed to roads based on the road class. Speed values attributed to sections of the road network are from the RSA $(2013)^{3}$ free speed survey, which publishes average car speeds by road class ${ }^{4}$. This speed survey monitors the free speeds (speeds at which drivers choose to travel when unconstrained by road geometry, weather conditions or traffic conditions) of vehicles in both urban and rural areas.

Galway County Council collected detailed daily data on the effects of flooding on the road network within the County ${ }^{5}$. The council set up an ArcGIS app which allowed locally based staff to upload flood details. Office based staff then added information about road closures. This information was combined with interactive maps and made available to the public through a link on the Council website (National Directorate for Fire and Emergency Management, 2016). The data contains information on whether a road is open, closed, passable or only one-lane open. A unique identifier is given for each road segment affected and the data is time stamped. The data covers a 17 working day period of disruption and is time stamped (9th December 2015 to 5th January 2016). In some cases the data was updated twice daily (morning and afternoon). This data was then linked to Galway Road Network data $^{6}$. The OpenStreetMap dataset is used as it is a richer dataset compared to the Galway Road Network data. The OpenStreetMap does not contain the unique road numbering identifier (DoTTS, 2013) required to match the flooded road data. The flooded roads data was firstly matched to the Galway Road Network Data using the unique road numbering identifier. These flooded roads are then converted from polyline to rasterised data using $5 \mathrm{~m}$ pixels. This raster data is attributed to the overlapping OpenStreetMap polyline using the Zonal Statistics as a table function. This process overlays the Galway Road Network with the OpenStreetMap and assigns a unique road numbering identifier to all overlapping roads in the OpenStreetMap data.

In order to calculate the time it takes to travel a segment of road, speed and distance is used. For each segment of the road network the time it takes in minutes to travel that segment is recorded using the following formula.

$$
\text { Time }=\frac{\text { Distance }}{\text { Speed }}
$$

A Network Dataset (ND) is created in ArcMap using the create ND function. Turns or restrictions are not modelled in the dataset and time rather than distance is used as the impedance factor. The resulting OpenStreetMap Data contains information on road status (Open, close, passable), average speed, distance and time.

\section{Calculation of the Origin-Destination Cost Matrix}

Similar to other studies (Ford et al., 2015b) the centroid of each electoral division (ED) in County Galway is used as the origin and destination points. Where an origin/destination point does not overlap with a road, the centroid is snapped to the closest road segment. An OD cost matrix was then calculated for the 234 EDs in County Galway. The calculated OD cost

\footnotetext{
See Appendix Table 8

${ }^{4}$ Five road classes are included in the model; Motorway, National Primary, National Secondary, Regional and

Local. Where road class is missing, road is labelled local road.

${ }^{5}$ https://data.gov.ie/dataset/floodedroadsdec2015

${ }^{6} \mathrm{https}: / /$ data.gov.ie/dataset/galway-county-roads-networkc9c86
} 
matrix was combined with the POWSCAR data to estimate actual commuting patterns in our study area - i.e. average journey times and distances travelled to work for commuters living in each ED. This gives us a status-quo estimate of commuting patterns in County Galway in the absence of any disruptions to the road network.

The OD-cost matrix procedure described above was then re-run accounting for the disruptions to the road network caused by the flooding. In practical terms, this involves removing road segments that were impassable, and reducing the average speed where the road was partially flooded. In a literature review of flood depth a speed of between 6 to 18 $\mathrm{km} / \mathrm{h}$ was found for small cars (Pregnolato et al., 2017b). A speed of $10 \mathrm{~km} / \mathrm{h}$ is used which is within that range. The status of affected roads was updated eleven times by Galway County Council during the 17 working day period studied. The OD model is re-run eleven times; each run with an updated configuration of available routes and speeds.

\subsection{Results}

The first part of the analysis focuses on the impacts of the flooding across space. The second part examines the distributional and individual impacts. This ensures there is between and within area analysis of flooding on commuting. Using data from SMILE enables us to examine the distributional impacts of the flooding across socio-economic groups. Individuals can be analysed using income, socio-economic and demographic characteristics and journey times. Results are aggregated at the electoral division level using commuter's origin.

\section{Results (1) - Spatial impacts of flooding on commuting costs}

Comparing the status quo journey time for each commuter with the journey time after the disruption the average additional journey time per commuter per day is calculated for each ED. After the commuting disruption, some commuters spend an extra 30-60 minutes per day commuting [Figure 1]. Commuters living in the areas around Gort to the south of Galway city, and Headford to the north (Galway city commuter zones) faced the biggest increase in journey times. According to local media these were also the worst affected areas (Galway Bay FM Newsroom, 2015). Mapping from the Copernicus Emergency Management Service illustrates the extent of the flooding $(\mathrm{EC}, 2015)$ in south county Galway.

\section{Figure 1: Additional time commuting due to floods}

\section{[Insert figure 1 here]}

Status quo commute time subtracted from commute time post Storm Desmond. Average time per commuter per ED

The results are aggregated based on an urban-rural classification [table 3]. As the table shows, the effect of the disruption due to flooding on commuters living in Galway city was relatively small. In contrast, commuters living in rural areas and small towns or villages were worst affected. The additional journey time for commuters living in villages was 157 minutes on average, due to the flooding, compared to just 10 additional minutes commuting time due to flooding on average for those living in Galway city. Not surprisingly, the table shows that those living in rural areas already had longer commutes under the status quo ( $\mathrm{J}$ time normal) relative to their urban counterparts. However, the impact of the flooding on commuting time was still more severe for the rural residents, even relative to normal journey times. For commuters living in villages, commuting time increased by $27 \%$ on average relative to 
normal circumstances, as a result of the flooding, while in the city the relative increase in commuting time was just $4 \%$ on average.

Table 3: Estimated additional journey times due to flooding, by Urban-Rural Classification of commuters over 17 day period

\begin{tabular}{|c|c|c|c|c|c|}
\hline Location & $\begin{array}{l}\text { Total } \\
\text { Commuters }\end{array}$ & $\begin{array}{l}\text { Proportion of } \\
\text { commuters }\end{array}$ & $\begin{array}{l}\text { Mean J time } \\
\text { Normal } \\
\text { (minutes) } \\
\end{array}$ & $\begin{array}{l}\text { Mean J time } \\
\text { Flood (minutes) }\end{array}$ & $\begin{array}{l}\% \text { Change in } \\
\text { mean J time }\end{array}$ \\
\hline Rural & 9,033 & 0.24 & 625 & 738 & $18 \%$ \\
\hline $\begin{array}{ll}\text { Village } & (200 \\
1,499) & \end{array}$ & 5,448 & 0.14 & 585 & 742 & $27 \%$ \\
\hline $\begin{array}{ll}\text { Town } & (1,500 \\
2,999) & \end{array}$ & 1,810 & 0.05 & 542 & 673 & $24 \%$ \\
\hline $\begin{array}{l}\text { Town } \\
4,999)\end{array}$ & 3,492 & 0.09 & 374 & 390 & $4 \%$ \\
\hline $\begin{array}{ll}\text { Town } & (5,000 \\
9,999) & \\
\end{array}$ & 2,544 & 0.07 & 570 & 649 & $14 \%$ \\
\hline Galway City & 15,833 & 0.41 & 228 & 238 & $4 \%$ \\
\hline
\end{tabular}

Source: Author Calculations

$\mathbf{J}$ time Normal is total commute time over a 17 day period using status quo conditions. $\mathbf{J}$ time Flood is total commute time post flooding over the 17 day period. Figures are mean times per commuter, using all commuters in that urban-rural classification

Commuting times and distances are then converted to monetary costs using SVTT and transport costs per $\mathrm{km}$, this information is then combined with simulated income data from SMILE. This gives an estimate of a commuter's costs both before and after the flood disruption. The additional commuting costs of the disruption as a percentage of the daily working wage is calculated. In the worst affected areas these costs represent $10 \%$ to $38.5 \%$ of the daily working wage [Figure 2]. The figure shows clearly the concentration of the impact (additional commuting costs relative to incomes) in the commuter belt to the north and south of Galway city. This finding highlights the vulnerability to disruptions of commuters living in rural areas, where a lack of transport alternatives can result in an overreliance on the private car.

\section{Figure 2: Additional commuting costs due to floods as \% of work income}

\section{[insert figure 2 here]}

Additional commuting time and distance as a result of flooding converted into monetary cost and presented as a percentage of total work income over 17 day period

\section{Results (2) Distribution of flood impacts}

In the first part of the results there was a focus on the geographic nature of the disruption. In this section there is a greater focus on the distributional impact of the flood event on the income distribution and overall inequality.

As a first step, the relationship between the size of the disruption caused by the floods with various socio-economic characteristics is measured at the individual level, using a set of simple cross-sectional regressions of the following form:

$$
D_{c p}=\alpha+\beta \boldsymbol{X}_{c p}+E D_{p}+\varepsilon_{c p}
$$


where ${ }_{D c p}$ represents the disruption due to flooding for individual commuter $c$ in location $p$, measured in various ways, as discussed further below, and $x_{c p}$ is a vector of individual level socio-economic characteristics. Some of the specifications include ED fixed effects.

In our first set of regression results [Table 4] those already with long commutes under the status quo, are disproportionately affected by the flood disruptions. In general, long commutes (under status quo) are associated with higher income, higher education, and being (relatively) young (column 1 of Table 4). This same pattern also holds for the effects of the floods (columns 2-4 of Table 4), this is not surprising as from the previous table these effects are increasing in normal commute time.

Table 4: Estimated relationship between journey time under status quo (column 1) and taking account of flood disruption (columns 2-5) with various socio-economic characteristics, measured at the individual level

\begin{tabular}{|c|c|c|c|c|}
\hline & (1) & (2) & (3) & (4) \\
\hline Variables & $\begin{array}{l}\text { Total Journey Time } \\
\text { (Normal) }\end{array}$ & $\begin{array}{l}\text { Total Journey Time } \\
\text { (Event) }\end{array}$ & $\begin{array}{l}\Delta \text { in Journey } \\
\text { Time }\end{array}$ & $\begin{array}{l}\Delta \Delta \quad \text { Journey } \\
\text { Time }(\%)\end{array}$ \\
\hline \multirow[t]{2}{*}{$\begin{array}{l}\text { Disposable Income } \\
(\mathrm{\prime} 000)\end{array}$} & $1.489 * * *$ & $1.943 * * *$ & $0.454 * * *$ & $0.068 * * *$ \\
\hline & $(0.121)$ & $(0.148)$ & $(0.052)$ & $(0.012)$ \\
\hline \multirow[t]{2}{*}{ Age } & $17.832 * * *$ & $21.468 * * *$ & $3.636 * * *$ & $0.435 * * *$ \\
\hline & $(1.18)$ & $(1.443)$ & $(0.513)$ & $(0.113)$ \\
\hline \multirow[t]{2}{*}{ Age2 } & $-0.190 * * *$ & $-0.228 * * *$ & $-0.038 * * *$ & $-0.003 * *$ \\
\hline & $(0.014)$ & $(0.017)$ & $(0.006)$ & $(0.001)$ \\
\hline \multirow[t]{2}{*}{ Tertiary Education } & $17.719 * * *$ & $24.573 * * *$ & $6.854 * * *$ & -0.042 \\
\hline & $(3.866)$ & $(4.728)$ & $(1.682)$ & $(0.371)$ \\
\hline \multirow[t]{2}{*}{ Owner Occupier } & $-36.921 * * *$ & $-49.763 * * *$ & $-12.842 * * *$ & $-3.447 * * *$ \\
\hline & $(5.679)$ & $(6.944)$ & $(2.47)$ & $(0.545)$ \\
\hline Observations & 39,538 & 39,538 & 39,538 & 39,538 \\
\hline R-Squared & 0.014 & 0.015 & 0.006 & 0.003 \\
\hline
\end{tabular}

Commuting costs of flooding as $\%$ of disposable income is shown to decrease in income (so higher earners are relatively less impacted) [Table 5]. This result contrasts with the earlier finding that the size of the disruption due to flooding, in terms of additional time, was increasing in income. However, the results in Table 5 indicate that the relative value of this disruption - i.e. the welfare effect - is larger for those on lower incomes. Specifically, the results show that for each extra $€ 1000$ in disposable income, the additional cost of the flood as $\%$ of income goes down $\sim 3.6 \%$ (column 1 of Table 5). This income effect is slightly stronger within EDs, at about $4 \%$ (columns 2 and 4 of Table 5) and holds when controlling for other socio-economic characteristics such as age, education and housing tenure (columns 3 and 4 of Table 5). 
Table 5: Estimated relationship between the change in commuting costs due to flooding (as a \% of disposable income) with various socio-economic characteristics, measured at the individual level.

\begin{tabular}{|c|c|c|c|c|}
\hline & (1) & (2) & (3) & (4) \\
\hline Variables & $\begin{array}{l}\Delta \text { in Journey Cost } \\
\text { as } \% \text { Income }\end{array}$ & $\begin{array}{l}\Delta \text { in Journey Cost } \\
\text { as } \% \text { Income }\end{array}$ & $\begin{array}{l}\Delta \text { in Journey Cost } \\
\text { as } \% \text { Income }\end{array}$ & $\begin{array}{l}\Delta \text { in Journey Cost } \\
\text { as } \% \text { Income }\end{array}$ \\
\hline \multirow[t]{2}{*}{$\begin{array}{l}\text { Disposable } \\
\text { Income ('000) }\end{array}$} & $-0.0036 * * *$ & $-0.0040 * * *$ & $-0.0040 * * *$ & $-0.0043 * * *$ \\
\hline & & & $(0.000)$ & $(0.000)$ \\
\hline \multirow[t]{2}{*}{ Age } & & & $0.018 * * *$ & $0.012 * * *$ \\
\hline & & & $(0.002)$ & $(0.002)$ \\
\hline \multirow[t]{2}{*}{ Age2 } & & & $-0.000 * * *$ & $-0.000 * * *$ \\
\hline & & & $(0.000)$ & $(0.000)$ \\
\hline \multirow[t]{2}{*}{$\begin{array}{l}\text { Tertiary } \\
\text { Education } \\
\end{array}$} & & & $0.027 * * *$ & $0.029 * * *$ \\
\hline & & & $(0.007)$ & $(0.006)$ \\
\hline \multirow[t]{2}{*}{$\begin{array}{l}\text { Owner } \\
\text { Occupier }\end{array}$} & & & $-0.043 * * *$ & 0.000 \\
\hline & & & $(0.010)$ & $(0.008)$ \\
\hline $\begin{array}{ll}\text { ED } & \text { Fixed } \\
\text { Effects } & \\
\end{array}$ & & YES & & YES \\
\hline Observations & 39,538 & 39,538 & 39,538 & 39,538 \\
\hline R-Squared & 0.008 & 0.374 & 0.01 & 0.376 \\
\hline $\begin{array}{l}\text { Standard errors } i \\
* * * p<0.01, * * p\end{array}$ & $\begin{array}{l}\text { parentheses } \\
.05, * p<0.1\end{array}$ & & & \\
\hline
\end{tabular}

Figure 3: Lorenz Curves of work income for the 17 day period before and after commuting, including flood disruption

\section{[Insert figure 3 here]}

Figure 3 and Table 6 illustrate the increasing inequality post flood event. The Lorenz curve shifts outwards after the inclusion of commuting costs [Figure 3] and again after the disruption. This gap decreases further up the income distribution, illustrating how lower income groups are disproportionately impacted by the disruption.

Table 6: Percentage Share of Income attributed to each quintile grou

\begin{tabular}{|l|l|l|l|l|l|l|}
\hline & \multicolumn{2}{l|}{ Period Income } & \multicolumn{2}{l|}{ Commuting } & \multicolumn{2}{l|}{ Commuting After Flood } \\
\hline Quintile Group & \% of Median & Share \% & \% of Median & Share \% & \% of Median & Share \% \\
\hline 1 & 37 & 2.3 & 24 & 1.2 & 20 & 0.9 \\
\hline 2 & 55 & 4.1 & 43 & 2.7 & 39 & 2.5 \\
\hline 3 & 72 & 6.0 & 62 & 4.5 & 59 & 4.2 \\
\hline 4 & 85 & 6.9 & 82 & 6.2 & 80 & 6.0 \\
\hline 5 & 100 & 8.4 & 100 & 7.8 & 100 & 7.7 \\
\hline 6 & 116 & 9.7 & 120 & 9.4 & 121 & 9.4 \\
\hline 7 & 131 & 11.1 & 143 & 11.3 & 145 & 11.3 \\
\hline
\end{tabular}




\begin{tabular}{|l|l|l|l|l|l|l|}
\hline 8 & 149 & 12.6 & 168 & 13.3 & 172 & 13.5 \\
\hline 9 & 179 & 14.6 & 210 & 16.0 & 216 & 16.3 \\
\hline 10 & & 24.2 & & 27.7 & & 28.3 \\
\hline
\end{tabular}

Source: Author Calculations

Table 7 examines the impact of commuting and the disruption on overall inequality. Commuting and the flood disruption have increased the overall level of inequality. The monetary cost of travel has a greater impact on inequality compared to the time costs. Overall, commuting is regressive, increasing inequality from 0.293 (when work income is considered) to 0.473 (after commuting and the flood disruption). The Theil index is used to analyse population subgroups. Inequality can be easily decomposed into the amount of variability attributed to the different population subgroups (Shorrocks, 1980; Shorrocks, 1982). The majority of the variation in income and costs can be explained between individuals rather than between areas. This would suggest a large variation in travel times and distances even within an area. This trend holds for commuting before and after the travel disruption. The Reynolds-Smolensky index measures the progressivity or regressivity of a measure by examining the difference in Gini of pre- and post-measure incomes (Reynolds and Smolensky, 1977). The increased Gini coefficient and negative sign on the ReynoldsSmolensky measure confirms the regressive nature of commuting and the disruption.

Table 7: Theil Decomposition Index of Inequality, showing market work income plus travel costs before and after the flood event

\begin{tabular}{|l|l|l|l|l|l|}
\hline Period Income and Costs & I2 Index & Within \% & Between \% & Gini & $\begin{array}{l}\text { Reynolds- } \\
\text { Smolensky }\end{array}$ \\
\hline Market Work Income & 0.293 & $80.2 \%$ & $20.3 \%$ & 0.327 & 0 \\
\hline Normal Scenario: & & & & & \\
\hline Monetary cost travel & 0.386 & $81.3 \%$ & $19.2 \%$ & 0.361 & -0.034 \\
\hline Time cost travel & 0.321 & $80.9 \%$ & $19.7 \%$ & 0.340 & -0.012 \\
\hline Total cost of travel & 0.439 & $81.7 \%$ & $18.9 \%$ & 0.377 & -0.050 \\
\hline After Flooding: & & & & & \\
\hline Monetary cost travel & 0.403 & $81.2 \%$ & $19.3 \%$ & 0.364 & -0.037 \\
\hline Time cost travel & 0.326 & $80.9 \%$ & $19.6 \%$ & 0.341 & -0.013 \\
\hline Total cost of travel & 0.473 & $81.4 \%$ & $19.2 \%$ & 0.383 & -0.056 \\
\hline
\end{tabular}

Normal scenario is status quo conditions over a 17 day period, after flooding takes into account extra time and travel costs. Monetary, time and total costs are each subtracted from market work income to generate various inequality indices.

\subsection{Conclusions}

The flooding event had a significant impact on commuting times and costs. Those living in rural areas and small towns and villages were greatly impacted. In worst affected areas, extra costs were up to $39 \%$ of earnings for the period. The areas of the Galway city commuter belt north and south may suggest a proximity to city effect. Those living in rural areas are more at risk to travel disruptions due to longer commuting times. These areas are also served poorly by public transport so have few alternatives to using the car. The disruption costs are unequally distributed, with those already with large commuting costs burdened with extra costs. The disruption also increased inequality with those on lower incomes suffering proportionately greater losses. Poor households may be forced to live in risky areas. These areas may warrant further investigation to determine if there is a discount on house prices in these areas. 
The results are consistent with the narrative that low income groups are most vulnerable to weather shocks such as flooding. This paper highlights that even within a developed country such as Ireland, those in the low-middle income groups are most at risk. This research makes two important findings; firstly the costs imposed on commuters from a flooding event represent a sizeable portion of their wages. Secondly these costs are not spread equally across income groups. Similar to indirect taxes (i.e. value added tax), commuting costs have a regressive impact on inequality. Those already facing long commutes combined with a low income are most vulnerable to extreme weather disruptions. The frequency of disruptions caused by Storms Desmond, Eva and Frank are likely to increase due to climate change (van Oldenborgh et al., 2015). Policy intervention may be required for those in low income groups to ease the burden of the extra costs, while the distributional impact identified here should be taken into account in the formulation of flood risk management plans and climate change adaptation strategies.

Given the number of National roads affected more infrastructure advancements should be made to ensure the road network is more resilient to extreme weather events such as Storm Desmond. A vulnerability analysis similar to the one by Jenelius and Mattsson (2012) can help identify critical nodes while an impact assessment of climate change on future transport disruptions can test the resilience of the road network (Lhomme et al., 2013). Planning considerations should be made towards reducing commuting times, either by increasing public transport provision or reducing the distance between areas of residence and areas of work. More flexible working arrangements could also be put in place whereby workers affected could work remotely. Such an arrangement can reduce commuters costs (Caulfield, 2015). In the analysis we are unable to differentiate between the likelihood of a worker being late or absent. The calculation of journey times assumes that every commuter travelled to work on each working day during the period of disruption. This assumption may underestimate absenteeism because of the disruption. In the aftermath of widespread flooding in central Europe in June 2013, businesses reported 60\% of their workforce were affected either by being absent or late from work (Thieken, 2016).

The data utilised for this study included time stamped spatial data on flooding impacts to the road network and highlights the collecting detailed spatial information. This paper illustrates a method whereby the costs of extreme weather events can be measured by adding a spatial component to open source data.

This study highlights the significant costs to commuters associated with the impact of a flood disruption on the transport network. The distributional impacts of the disruptions identified here are also of relevance to policy-makers tasked with developing flood risk management plans and climate change adaptation strategies. However, further research is required to better understand the full impact of extreme weather events across income groups.

\section{References:}

AA. (2016) Cost of Motoring. Available at: http://www.theaa.ie/aa/motoring-advice/cost-ofmotori ng.aspx.

Arkell B and Darch G. (2006) IMPACTS OF CLIMATE CHANGE ON LONDON'S TRANSPORT SYSTEMS. Proceedings of the ICEMunicipal Engineer 159: 231-237.

Atkinson AB. (1983) The economics of inequality: JSTOR.

Ballas D, Clarke G, Dorling D, et al. (2007) Using SimBritain to model the geographical impact of national government policies. Geographical Analysis 39: 44-77.

Barr NA. (1998) The economics of the welfare state: Stanford University Press.

Becker GS. (1965) A Theory of the Allocation of Time. The economic journal: 493-517. 
Birkin M and Clarke G. (2012) The enhancement of spatial microsimulation models using geodemographics. The Annals of Regional Science: 1-18.

Brady J and O'Mahony M. (2011) Travel to work in Dublin. The potential impacts of electric vehicles on climate change and urban air quality. Transportation research part $D$ : transport and environment 16: 188-193.

Caulfield B. (2015) Does it pay to work from home? Examining the factors influencing working from home in the Greater Dublin Area. Case Studies on Transport Policy 3: 206-214.

CCRA. (2012) UK Climate Change Risk Assessment: Government Report. In: Department for Environment FRA (ed). London.

Chin S-F and Harding A. (2006) Regional dimensions: creating synthetic small-area microdata and spatial microsimulation models: National Centre for Social and Economic Modelling.

Cochrane HC. (1975) Natural hazards and their distributive effects: Institute of Behavioral Science, University of Colorado Boulder.

CSO. (2011) Census 2011 Place of Work, School or College - Census of Anonymised Records (PO WS CAR). Available at: http://www.cso.ie/en/census/census2011placeofworkschoolorcollegecensusofanonymisedrecordspowscar/.

CSO. (2013) Survey on Income and Living Conditions (SILC): 2011 \& revised 2010 results. Central Statistics Office.

Dawson RJ, Thompson D, Johns D, et al. (2018) A systems framework for national assessment of climate risks to infrastructure. Phil. Trans. R. Soc. A 376: 20170298.

Debionne S, Ruin I, Shabou S, et al. (2016) Assessment of commuters' daily exposure to flash flooding over the roads of the Gard region, France. Journal of Hydrology 541: 636-648.

DfT. (2014) TAG UNIT A2.1: Wider Impacts. In: Transport Do (ed) Transport Analysis Guidance. London, UK.

DoTTS. (2013) Guidelines for Classification and Scheduling of Roads In Ireland. In: Department of Transport TaS (ed). Dublin, Ireland.

EC. (2015) EMSR149: Flood in Ireland. Available at: http://emergency.copernicus.eu/mapping/list-ofcomponents/EMSR149.

Esposito A. (2016) Assessing impacts of flood events in urban areas to understand the resilience of the urban system.

Farrell N, Morrissey K and O'Donoghue C. (2013a) Creating a Spatial Microsimulation Model of the Irish Local Economy. Spatial Microsimulation: A Reference Guide for Users: 105-125.

Farrell N, Morrissey K and O'Donoghue C. (2013b) Simulated model for the Irish local economy. Microsimulation Methods and Models, London, Springer.

Farrell N, O'Donoghue C and Morrissey K. (2010) Spatial microsimulation using quota sampling. Tea gasc rural economy research series working paper 7.

FEMA. (2001) Earthquake Loss Estimation Methodology (HAZUS). In: Agency FEM (ed). Washington, DC: National Institute of Building Sciences.

Ferreira S, Hamilton K and Vincent JR. (2011) Nature, socioeconomics and adaptation to natural disasters: new evidence from floods.

Field CB, Barros VR, Mach K, et al. (2014) Climate change 2014: impacts, adaptation, and vulnerability: Cambridge University Press Cambridge and New York.

Ford A, Jenkins K, Dawson R, et al. (2015a) Simulating Impacts of Extreme Weather Events on Urban Transport Infrastructure in the UK. UCL STEaPP.

Ford AC, Barr SL, Dawson RJ, et al. (2015b) Transport accessibility analysis using GIS: Assessing sustainable transport in London. ISPRS International Journal of Geo-Information 4: 124-149.

Galway Bay FM Newsroom. (2015) UPDATE 4.30pm: Galway city and county flood alerts. Connacht Tribune. Galway.

Gordon P, Richardson HW and Davis B. (1998) Transport-related impacts of the Northridge earthquake: National Emergency Training Center Los Angeles, CA. 
Guerreiro SB, Dawson RJ, Kilsby C, et al. (2018) Future heat-waves, droughts and floods in 571 European cities. Environmental Research Letters 13: 034009.

Haklay M and Weber P. (2008) Openstreetmap: User-generated street maps. IEEE Pervasive Computing 7: 12-18.

Hallegatte S and Przyluski V. (2010) The economics of natural disasters: concepts and methods.

Harris R, O'Sullivan D, Gahegan M, et al. (2017) More bark than bytes? Reflections on 21+ years of geocomputation. Environment and Planning B: Urban Analytics and City Science 44: 598-617.

Hazans M. (2004) Does commuting reduce wage disparities? Growth and Change 35: 360-390.

Impact Trade Union. (2009) Motor Mileage Rates. Available at: http://www.impact.ie/membersinfo/pay-incomes/travel-subsistence/civil-servcie-mileage-and-subsistence-rates/.

I PCC. (2007) IPCC Fourth Assessment Report. Available at: http://www.ipcc.ch/pdf/assessmentreport/a r4/wg1/a r4 wg1 full report. pdf.

IPCC. (2012) Managing the risks of extreme events and disasters to advance climate change adaptation. In: Change IDoC (ed).

IPCC. (2013) Climate Change 2013: The Physical Science Basis. Summary for Policymakers. Available at: http://www.climatechange2013.org/images/report/WG1AR5ALLFINAL.pdf.

Jaroszweski D, Hooper E and Chapman L. (2014) The impact of climate change on urban transport resilience in a changing world. Progress in Physical Geography 38: 448-463.

Jenelius E and Mattsson L-G. (2012) Road network vulnerability analysis of area-covering disruptions: A grid-based approach with case study. Transportation research part A: policy and practice $46:$ : 746-760.

Jenelius E and Mattsson L-G. (2015) Road network vulnerability analysis: Conceptualization, implementation and application. Computers, Environment and Urban Systems 49: 136-147.

Jongman B, Winsemius HC, Aerts JC, et al. (2015) Declining vulnerability to river floods and the global benefits of adaptation. Proceedings of the National Academy of Sciences 112: E2271-E2280.

Kahn ME. (2005) The death toll from natural disasters: the role of income, geography, and institutions. Review of economics and statistics 87: 271-284.

Kain JF. (1962) The journey-to-work as a determinant of residential location. Papers in Regional Science 9: 137-160.

Kelly JA and Fu M. (2014) Sustainable school commuting-understanding choices and identifying opportunities: A case study in Dublin, Ireland. Journal of Transport Geography 34: 221-230.

Kermanshah A, Karduni A, Peiravian F, et al. (2014) Impact analysis of extreme events on flows in spatial networks. Big Data (Big Data), 2014 IEEE International Conference on. IEEE, 29-34.

Lhomme S, Serre D, Diab Y, et al. (2013) Analyzing resilience of urban networks: a preliminary step towards more flood resilient cities. Natural hazards and earth system sciences 13: 221-230.

Lucas JL and Heady RB. (2002) Flextime commuters and their driver stress, feelings of time urgency, and commute satisfaction. Journal of Business and Psychology 16: 565-571.

Lyons $\mathrm{G}$ and Chatterjee K. (2008) A human perspective on the daily commute: costs, benefits and trade-offs. Transport Reviews 28: 181-198.

Marsden G, Anable J, Shires J, et al. (2016) Travel Behaviour Response to Major Transport System Disruptions: Implications for Smarter Resilience Planning. OECD/International Transport Forum Roundtable on Preparing for Major Disruptions to Transport Systems.

Masozera M, Bailey M and Kerchner C. (2007) Distribution of impacts of natural disasters across income groups: A case study of New Orleans. Ecological Economics 63: 299-306.

Met Éireann. (2016) Weather Summary Winter 2016. In: Éireann M (ed). Dublin, Ireland.

Morrissey K, O'Donoghue C, Clarke G, et al. (2013) Using Simulated Data to Examine the Determinants of Acute Hospital Demand at the Small Area Level. Geographical Analysis 45: 49-76.

Morrissey K and O'Donoghue C. (2011) The spatial distribution of labour force participation and market earnings at the sub-national level in Ireland. Review of Economic Analysis 3: 80-101. 
National Directorate for Fire and Emergency Management. (2016) Report on Flooding December 4 2015 - January 13 2016. In: Department of Housing P, Community and Local Government (ed).

NOAA. (2017) State of the Climate: Global Analysis for Annual 2016. Available at: http://www.ncdc.noaa.gov/sotc/global/201613.

NTA. (2011) New National Car Sharing Website Launched. Dublin, Ireland: National Transport Authority.

O'Donoghue C, Ballas D, Clarke G, et al. (2012) Spatial microsimulation for rural policy analysis: Springer Science \& Business Media.

O'Donoghue C, Ballas D, Clarke G, et al. (2013) Spatial microsimulation for rural policy analysis: Springer.

O'Donoghue C, Farrell N, Morrissey K, et al. (2013) The SMILE Model: Consturction and Calibration. In: O'Donoghue C, Ballas D, Clarke G, et al. (eds) Spatial Microsimulation for Rural Policy Analysis. Springer, 55-86.

OECD. (2014) Seine Basin, Île-de-France, 2014: Resilience to Major Floods: OECD Publishing.

OPW. (2009) Report of flooding at Labane area Co Galway Novemberf 2009. Available at:

http://floods.ie/View/FloodReports.aspx?Type=Reports\&Floodld=10806.

OPW. (2016) Floods.ie. Available at: http://floods.ie.

Partridge MD and Rickman DS. (1998) Regional computable general equilibrium modeling: a survey and critical appraisal. International Regional Science Review 21: 205-248.

Pope C. (2016) Floods in Athlone: 'I've had enough. I can't take any more'. The Irish Times. Dublin, Ireland.

Pregnolato M, Ford A and Dawson R. (2016) Disruption and adaptation of urban transport networks from flooding. E3S Web of Conferences. EDP Sciences, 07006.

Pregnolato M, Ford A, Glenis V, et al. (2017a) Impact of Climate Change on Disruption to Urban Transport Networks from Pluvial Flooding. Journal of Infrastructure Systems 23: 04017015.

Pregnolato M, Ford A, Wilkinson SM, et al. (2017b) The impact of flooding on road transport: a depth-disruption function. Transportation research part D: transport and environment 55 : 67-81.

Reynolds M and Smolensky E. (1977) Public expenditures, taxes, and the distribution of income: The United States, 1950, 1961, 1970: Academic Press.

Rose A. (2004) Economic principles, issues, and research priorities in hazard loss estimation. Modeling spatial and economic impacts of disasters. Springer, 13-36.

Rose A, Benavides J, Chang SE, et al. (1997) The regional economic impact of an earthquake: Direct and indirect effects of electricity lifeline disruptions. Journal of Regional Science 37: 437-458.

RSA. (2013) Free Speed Survey (Urban and Rural).

Shorrocks AF. (1980) The class of additively decomposable inequality measures. Econometrica: Journal of the Econometric Society: 613-625.

Shorrocks AF. (1982) Inequality decomposition by factor components. Econometrica: Journal of the Econometric Society: 193-211.

So KS, Orazem PF and Otto DM. (2001) The effects of housing prices, wages, and commuting time on joint residential and job location choices. American Journal of Agricultural Economics 83: 1036-1048.

Stiglitz J, Sen A and Fitoussi J-P. (2009) Report by the Commission on the Measurement of Economic Performance and Social Progress. Available at: http://ec.europa.eu/eurostat/documents/118025/118123/Fitoussi+Commission+report.

Suzumura T, McArdle G and Kanezashi H. (2015) A high performance multi-modal traffic simulation platform and its case study with the Dublin city. Winter Simulation Conference (WSC), 2015. IEEE, 767-778.

Sweeney J, Albanito F, Brereton A, et al. (2008) Climate Change-Refining the Impacts for Ireland: STRIVE Report (2001-CD-C3-M1) ISBN: 978-1-84095-297-1. 
Tatano $\mathrm{H}$ and Tsuchiya S. (2008) A framework for economic loss estimation due to seismic transportation network disruption: a spatial computable general equilibrium approach. Natural Hazards 44: 253-265.

Thieken AH. (2016) The flood of June 2013 in Germany: how much do we know about its impacts? Natural hazards and earth system sciences 16: 1519.

van Oldenborgh GJ, Otto FE, Haustein K, et al. (2015) Climate change increases the probability of heavy rains like those of storm Desmond in the UK-an event attribution study in near-real time. Hydrology and Earth System Sciences Discussions 12: 13197-13216.

Vega A, Kilgarriff P, O'Donoghue C, et al. (2016) The spatial impact of commuting on income: a spatial microsimulation approach. Applied Spatial Analysis and Policy: 1-21.

Walker G and Burningham K. (2011) Flood risk, vulnerability and environmental justice: Evidence and evaluation of inequality in a UK context. Critical Social Policy 31: 216-240.

Watson D. (2005) Mapping Poverty: national, regional and county patterns: Combat Poverty Agency.

Winsemius HC, Jongman B, Veldkamp TI, et al. (2018) Disaster risk, climate change, and poverty: assessing the global exposure of poor people to floods and droughts. Environment and Development Economics: 1-21.

Zhu S, Levinson D, Liu HX, et al. (2010) The traffic and behavioral effects of the I-35W Mississippi River bridge collapse. Transportation research part A: policy and practice 44: 771-784.

\section{Appendix:}

Table 8: Road Safety Authority - Free Speeds by Road Class

\begin{tabular}{|l|l|l|}
\hline Road Type & $\begin{array}{l}\text { Speed Limit } \\
(\mathrm{km} / \mathrm{h})\end{array}$ & $\begin{array}{l}\text { Avg. } \\
(\mathrm{km} / \mathrm{h})\end{array}$ \\
\hline Urban national & 50 & 60 \\
\hline Urban national & 60 & 63 \\
\hline Urban arterial & 50 & 57 \\
\hline Urban arterial & 60 & 64 \\
\hline Residential & 50 & 40 \\
\hline Residential & 30 & 31 \\
\hline Motorway & 120 & 112 \\
\hline Dual Carriageway & 80 & 91 \\
\hline Dual Carriageway & 100 & 95 \\
\hline National Primary Road & 100 & 92 \\
\hline National Primary Road & 80 & 84 \\
\hline $\begin{array}{l}\text { National Secondary } \\
\text { Road }\end{array}$ & 100 & 85 \\
\hline Regional Roads & 80 & 77 \\
\hline Regional Roads & 50 & 53 \\
\hline Local Roads & 50 & 63 \\
\hline Local Roads & 60 & 56 \\
\hline
\end{tabular}

